\title{
Risk Factors for Complications of Drug-Induced Seizures
}

\author{
Josef G. Thundiyil • Freda Rowley • Linda Papa • \\ Kent R. Olson • Thomas E. Kearney
}

Published online: 27 July 2010

(C) The Author(s) 2010. This article is published with open access at Springerlink.com

\begin{abstract}
The purpose of this study is to determine clinical factors associated with complications of drug-induced seizures. This prospective observational study was conducted at an American Association of Poison Control Centers-certified regional poison control center (PCC) over a 1-year period. All consecutive cases reported to a PCC involving seizures were forwarded to investigators, who obtained standardized information including the specific drug or medication exposure, dose, reason for exposure, vital signs, laboratory data, treatment, and outcome. Patients were monitored by daily telephone follow-up until death or discharge. Subjects were excluded if the seizure was deemed to be unrelated to exposure. Odds ratios were used to analyze variables for associations with admission to the hospital for $>72 \mathrm{~h}$, endotracheal intubation, status epilepticus, anoxic brain injury, or death. One hundred twenty-one cases met inclusion criteria. Sixty-three (52\%) were male, and the mean age was 30 (SD14)years.
\end{abstract}

Presented as a poster at Society for Academic Emergency Medicine, Washington D.C., USA, May 2008

Funding: HRSA CFDA 93.253 Grant: H4BHS00029-05-01

J. G. Thundiyil • L. Papa

Department of Emergency Medicine,

Orlando Regional Medical Center, Orlando Health,

Orlando, FL, USA

J. G. Thundiyil • F. Rowley • K. R. Olson • T. E. Kearney

Department of Pharmacy, Division of Clinical Pharmacology,

University of California, San Francisco,

California Poison Control Systems,

San Francisco, CA, USA

J. G. Thundiyil $(\bowtie)$

86 W. Underwood St, Suite 200,

Orlando, FL 32806, USA

e-mail: joseft@mindspring.com
Common exposures included: antidepressants (33\%), stimulants $(15 \%)$, and anticholinergics $(10 \%)$. One hundred and three $(85 \%)$ of the exposures were intentional, of which 74 were suicide attempts and 16 were drug abuse or misuse. Forty-nine (40\%) patients required endotracheal intubation, $12(10 \%)$ had status epilepticus, 50(41\%) were hospitalized for more than $72 \mathrm{~h}$, and one patient died. Median hospital stay was 3 days. Variables significantly associated with complications included stimulant exposure (odds ratios, OR $=11[95 \%$ confidence intervals (CI) 1.9-52]), suicide attempt (OR=2.2 [95\% CI 1.02-4.7]), initial hypotension (OR $=11.2[95 \% \mathrm{CI}$ $1.4-89.3])$, admission glucose $>130 \mathrm{mg} / \mathrm{dL}(\mathrm{OR}=5.4[95 \% \mathrm{CI}$ 1.6-18.1]), and admission $\mathrm{HCO}_{3}<20 \mathrm{mEq} / \mathrm{L}(\mathrm{OR}=4.0[95 \%$ CI 1.4-11.3]). Significant clinical factors associated with complications of drug-related seizures include stimulant exposure, suicide attempt, initial hypotension, and admission acidosis or hyperglycemia.

Keywords Drug-induced seizures · Risk factors ·

Poison control center - Overdose

\section{Introduction}

It is estimated that $2-5 \%$ of the population will have at least one nonfebrile seizure in their lifetime [1]. It is the responsibility of the treating physician to terminate the seizure, prevent complications, identify life-threatening causes, determine disposition, and minimize morbidity and mortality for this condition [2]. Seizures are a serious complication associated with medication or drug use, which can result in hyperthermia, acidosis, anoxic brain injury, an eightfold risk of aspiration pneumonitis, and nearly $2 \%$ mortality $[3,4]$. A prospective study of status epilepticus revealed that ethanol and drug overdose is responsible for 
$18 \%$ of cases of status epilepticus with a fatality rate of over $20 \%$ [5]. It is estimated that $6.1 \%$ of new onset seizures are drug-related [6]. Other studies have determined that up to $9 \%$ of cases of status epilepticus presenting to the Emergency Department may result from drug toxicity, and drug-induced seizures may result in status epilepticus up to $5 \%$ of the time $[7,8]$. Additionally, changing prescription and drug abuse patterns are reflected in the incidence of substances attributable to seizures [4].

Currently, few studies help inform clinicians as to which drug-induced seizure patients are at greatest risk for complications and mortality. Retrospective studies have suggested that substance type and hyperthermia may be associated with mortality in this patient population, while others have maintained that age, anoxia, and duration of seizure in status epilepticus are predictors of mortality $[4,9,10]$. No prospective studies have been conducted on this topic. Ascertaining the probable clinical course and likelihood for complications related to drug-induced seizures can guide patient disposition decisions, foster cost-effective management, and optimize treatment.

The objective of this study was to determine risk factors associated with morbidity and mortality from drug-induced seizures. We defined a complicated hospital course as: admission to the hospital for greater than $72 \mathrm{~h}$ (for reasons other than psychiatric or social placement), the need for endotracheal intubation, development of status epilepticus, anoxic brain injury, or death. We sought to determine clinical factors of drug-induced seizures associated with a complicated hospital course.

\section{Materials and Methods}

Study Setting This prospective observational study was conducted at a single American Association of Poison Control Centers-certified regional poison control center over a 12-month period. The San Francisco Division of the California Poison Control System (SFCPCS) has served nearly a quarter of the population of California since 1997. The SFCPCS provides 24-h hotline service to the residents within its catchment area. It is consulted on over 70,000 cases annually involving exposure to drugs or potentially toxic substances. All hospitalized exposure cases are routinely followed by staff to assist with management and determine outcome. Staff members included pharmacists certified as specialists in poison information and medical toxicologists. The institutional review board at our affiliated university approved this study.

Selection of Participants The study population included all patients presenting with toxin or drug-induced seizure. All consecutive reported cases to the SFCPCS involving a seizure were included in this investigation. Callers were asked for specific patient care related clinical information necessary to correctly diagnose and treat the problem, according to our usual practice. The case was subsequently forwarded to investigators who obtained uniform information regarding: the drug, medication or toxin involved, estimated dose, time to treatment, patient demographics such as age and gender, reason for the exposure, a description of the seizure activity, who witnessed the seizure, the patient's past medical history, initial and subsequent vital signs, laboratory data, gastrointestinal decontamination methods, treatment provided, response to treatment, complications, and final outcome.

Investigators began collecting data within $12 \mathrm{~h}$ of the initial call, using a standardized data extraction form to ensure consistency of data collection and minimize bias. Since no gold standard for a tool of this type exists, the investigators created this form. Prior to initiating the study, the standardized form was used to extract data retrospectively from patient charts and then piloted prospectively on ten subjects. Based on these results, the form was modified for ease of use and to minimize interobserver variability. Blinding was not possible, since the investigators were also the data collectors. Data were obtained from health-care providers at the treating facility including physicians, nurses, physician's assistants, and laboratory personnel.

Patients were monitored by daily telephone follow-up with the admitting hospital until death or discharge in order to obtain information about clinical status, reasons for continued hospitalization, and complications. Cases were excluded if follow-up information was not available (i.e., if the patient discharged from the emergency department, and/or health-care workers were unable or unwilling to provide clinical information about the patient). Cases were also excluded if the seizure was determined not to be drug- or toxin-related using an adverse drug reaction (ADR) scoring system [11]. This ADR score is a wellaccepted method of determining causality for adverse drug events. A retrospective pilot study amongst three researchers on this project revealed good intraobserver reliability and is published previously as part of a separate study [4]. Of note, the causality classification was affected by the prior presence of an underlying seizure disorder. Subjects were excluded if the relationship between the seizure and exposure was determined to be "doubtful" or "coincidental." If more than one drug or medication was involved in the exposure, the substance with a previously described causal association with seizures was attributed as the most likely causal agent.

Outcome Measurement The primary outcome assessed was the development of a complicated hospital course. We 
defined this composite outcome measure as having one of the following: admission to the hospital for greater than $72 \mathrm{~h}$ (for reasons other than psychiatric or placement), the need for endotracheal intubation, status epilepticus, anoxic brain injury, or death. We did not consider admission to intensive care unit (ICU) by itself as a complication because previous experience had shown that criteria for ICU admissions for this patient population vary widely in our catchment area and often include convenience for suicide risk observation. As a secondary outcome measure, we evaluated the incidence of each of these complications independently (status epilepticus, endotracheal intubation, anoxic brain injury, and death).

We evaluated the impact of ten predictor variables on these outcomes. Predictors included gender, reason for exposure, substance type, primary decontamination method, initial antiepileptic medication given (after benzodiazepines), presence of initial acidosis, hyperthermia, rhabdomyolysis, hyperglycemia, or hypotension. For gender, male was used as the reference group. Hypotension was defined as an initial systolic blood pressure less than $90 \mathrm{mmHg}$. Acidosis was defined as initial $\mathrm{pH}<7.30$ or $\mathrm{HCO}_{3}<20 \mathrm{mEq} / \mathrm{L}$. Hyperthermia was defined as initial temperature greater than $38^{\circ} \mathrm{C}$. Rhabdomyolysis was defined as initial $\mathrm{CPK}>1,000 \mathrm{U} / \mathrm{L}$. Status epilepticus was defined operationally in accordance with previous studies as continuous or repeated seizure activity lasting greater than 10 min without recovery of consciousness [12]. Electroencephalogram confirmation was not required for classification. Substances were classified into one of six categories for purpose of analysis: antidepressant, antiepileptic, isoniazid, stimulant, anticholinergic, or other. These categories were selected based on a previously published dataset by the same authors reporting the epidemiology of drug-related seizures for this region [4].

Data Analysis We evaluated each predictor variable in a univariate analysis using odds ratios and $95 \%$ confidence intervals for associations with the main outcome. Variables which met $p$ values $<0.05$ were included in a logistic regression model to assess for independent associations with the composite outcome measure. For descriptive statistics, mean and standard deviation values were reported for normally distributed data, while median and interquartile ranges were used for nonparametric data. Univariate analyses were conducted using chi squared tests and odds ratios. Univariate and multivariate analyses were conducted using logistic regression. All analyses were performed using Epi Info (Version 3.4.3, 2007), Microsoft Excel 2008, and SAS (Version 9.1.3 for Windows). Based on an estimated complication rate of $50 \%$, a sample size of 124 was determined to be required to obtain $80 \%$ power.

\section{Results}

There were 138 patients with seizures reported to the SFCPCS during the study period. Investigators were notified of and able to follow up on 132 (96\%) of these. Two subjects were eliminated because of inadequate information. Another nine subjects were excluded because causality assessment deemed the seizure to be unrelated to the exposure. Of these nine excluded cases - five were found to have an underlying seizure disorder with medication noncompliance, one was determined to have pseudoseizures, and three had febrile seizures. This left 121 subjects available for inclusion into the analysis.

Table 1 details the frequency of specific exposures in this population. For purposes of analysis, all substances were categorized in one of six categories: antidepressants $(33.9 \%)$, stimulants $(14.9 \%)$, anticholinergics $(9.9 \%)$, INH (6.6\%), antiepileptic (11.6\%), or other (23.1\%).

Demographic features, presenting signs, initial treatment, and incidence of complications are presented in Table 2 . Thirteen of 14 patients who experienced aspiration pneumonia were also intubated. There was no difference in mean age between the complication group and noncomplicated group. Total number of patients who met the definition of having a complicated hospital course was $72(60 \%)$. Median length of hospital stay was 3 days (IQR, 2-5) overall; the length of stay was 2 days (IQR, 1-2) for the noncomplication group and 4 days (IQR, 3-6.25) for the complications group.

Table 1 Breakdown of exposures by substance $N=121$

\begin{tabular}{lc}
\hline Substance & Frequency (Number/\%) \\
\hline Tricyclic antidepressant & $2(1.7 \%)$ \\
Bupropion & $18(14.9 \%)$ \\
Venlafaxine & $2(1.7 \%)$ \\
Citalopram/escitalopram & $10(8.3 \%)$ \\
Quetiapine & $4(3.3 \%)$ \\
Other antidepressants & $4(3.3 \%)$ \\
Cocaine & $6(5.0 \%)$ \\
Amphetamine & $5(4.1 \%)$ \\
MDMA/Ecstasy & $3(2.5 \%)$ \\
Other Stimulant & $4(3.3 \%)$ \\
Isoniazid & $8(6.6 \%)$ \\
Tramadol & $2(1.7 \%)$ \\
NSAID & $1(0.8 \%)$ \\
Dextromethorphan & $3(2.5 \%)$ \\
Theophylline & $1(0.8 \%)$ \\
Antiepileptic & $15(12.4 \%)$ \\
Other & $22(18.2 \%)$ \\
Diphenhydramine & $8(6.6 \%)$ \\
Doxylamine & $3(2.5 \%)$ \\
\hline &
\end{tabular}


Table 2 Characteristics of study subjects $(N=121)$

\begin{tabular}{lc}
\hline Variable & Number (\%) \\
\hline Age (mean(SD)) & $30(14)$ \\
Gender (male) & $63(52 \%)$ \\
Number of substances (median(IQR)) & $1(1-3)$ \\
Reason & \\
Abuse & $16(13.2 \%)$ \\
Suicide & $74(61.2 \%)$ \\
Unintentional & $18(14.8 \%)$ \\
Presentation & \\
Acidosis & $40(33.1 \%)$ \\
Hypotension & $16(13.2 \%)$ \\
Hyperthermia & $22(18.2 \%)$ \\
Rhabdomyolysis & $21(17.4 \%)$ \\
Hypoglycemia & $3(2.5 \%)$ \\
Hyperglycemia & $23(19 \%)$ \\
Treatment & \\
Charcoal & $45(37.2 \%)$ \\
Whole bowel irrigation & $6(5 \%)$ \\
Gastric lavage & $11(9.1 \%)$ \\
Phenytoin & $12(9.9 \%)$ \\
Phenobarbital & $11(9.1 \%)$ \\
Benzodiazepine & $96(79.3 \%)$ \\
Complication & \\
Anoxic brain injury & $5(4.1 \%)$ \\
Aspiration pneumonia & $14(11.6 \%)$ \\
Coma & $43(35.5 \%)$ \\
Death & $1(0.8 \%)$ \\
Endotracheal intubation & $49(40.5 \%)$ \\
Status epilepticus & $12(9.9 \%)$ \\
\hline & \\
\hline &
\end{tabular}

Eighty subjects were admitted to the intensive care unit. The median length of ICU stay was 2 days (IQR, 0-3); 0 days (range, 0-3) for the noncomplication group and 3 days (range, 2-14) for the complications group. For subjects who were intubated, the median length of intubation was 2 days (IQR, 1-4; range, 1-12). Eight subjects were known to have an underlying seizure history. Information on time delay to presentation was available for only $23(19 \%)$ subjects. For all 23 of these subjects, there was an immediate EMS response with arrival of less than $15 \mathrm{~min}$.

Fifty-one subjects had coingestants. The number of exposed substances per subject ranged from 1 to 7 , with a median of 1 for each group. Of the coingestants: 18 were selective serotonin reuptake inhibitor antidepressants, 5 narcotics, 4 ethanol, 3 benzodiazepines, 3 carisoprodol, and 3 ibuprofen. The remainder of the coingestants was found to have only been ingested at therapeutic levels.

For initial treatment of seizures, 96 subjects were given a benzodiazepine ( 82 received lorazepam, 8 received diaze-

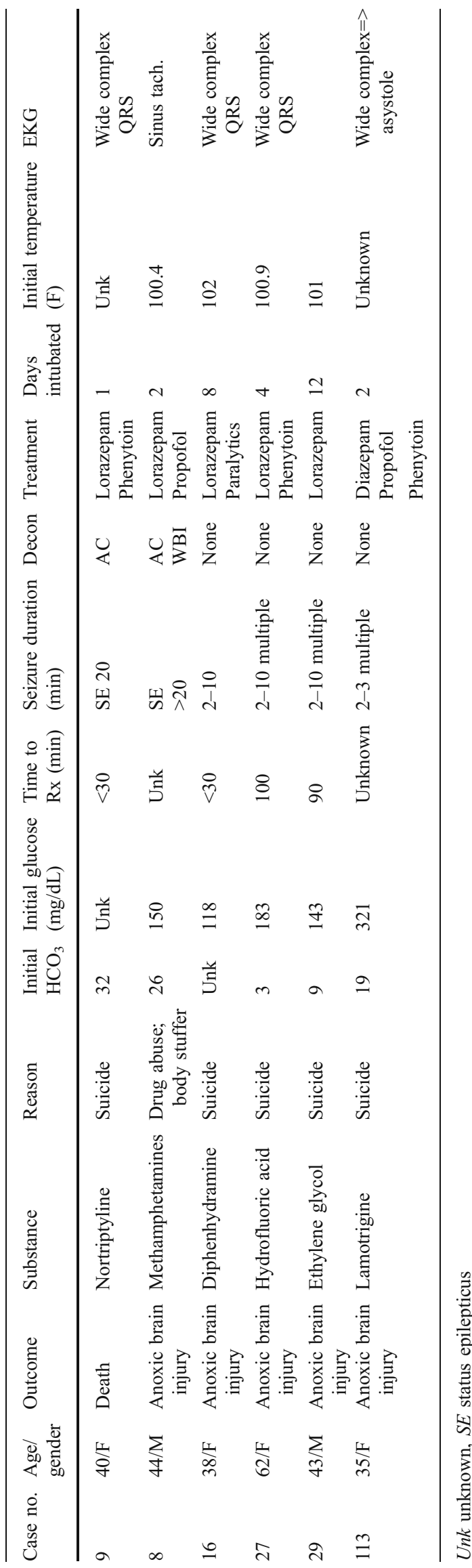




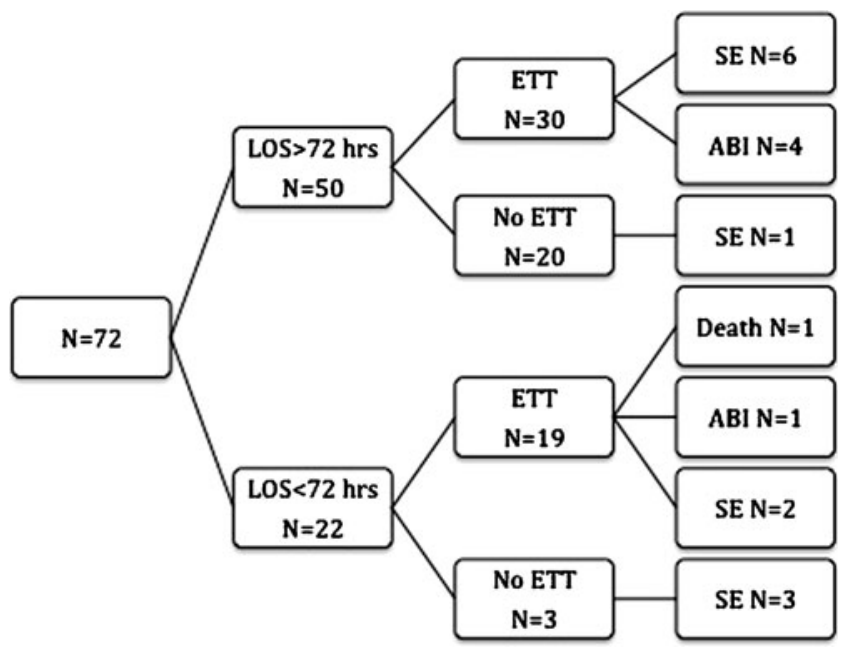

Fig. 1 Breakdown of study patients with complications. LOS length of stay, ETT endotracheally intubated, $S E$ status epilepticus, $A B I$ anoxic brain injury pam, 6 received midazolam), 3 received phenobarbital, 1 received pyridoxine, and 19 received no treatment. Twentynine of the subjects were given a medication strictly for seizure prophylaxis. Fifty-one subjects were given more than one drug for seizure termination. Seven subjects received paralysis in an attempt to control convulsions. Seizure termination was directly attributable to drug therapy in 64 subjects-43 from lorazepam, 7 from midazolam, 7 from diazepam, 5 from phenobarbital, and 2 from propofol.

Eight of the 12 subjects with status epilepticus were intubated, five developed hyperthermia, two developed aspiration pneumonia, one suffered an anoxic brain injury, and one died. Of the patients who experienced status epilepticus, six ingested a stimulant, one isoniazid, three tiagabine, one nortriptylline, and one bupropion. In this subgroup, seven were suicidal and three ingested the substance for purposes of abuse. Ten of the patients with status epilepticus were refractory to benzodiazepines.

All subjects with anoxic brain injury or death were intubated. Table 3 presents a description of these cases. Of

Table 4 Main results

\begin{tabular}{|c|c|c|c|c|}
\hline Predictor & $\begin{array}{l}\text { Complicated hospital } \\
\text { course* }(N=72)\end{array}$ & $\begin{array}{l}\text { Endotracheal } \\
\text { intubation }(N=49)\end{array}$ & $\begin{array}{l}\text { Anoxic brain } \\
\text { injury/death }(N=6)\end{array}$ & $\begin{array}{l}\text { Status epilepticus } \\
(N=12)\end{array}$ \\
\hline Gender & $1.0(0.5-2.1)$ & $1.1(0.5-2.4)$ & $2.1(0.4-12.2)$ & $0.8(0.2-2.5)$ \\
\hline \multicolumn{5}{|l|}{ Reason } \\
\hline Suicide & $1.8(0.9-3.9)$ & $1.8(0.9-4.0)$ & $1.3(0.2-7.4)$ & $0.9(0.3-2.9)$ \\
\hline Abuse & $1.6(0.5-4.8)$ & $2.4(0.8-7.1)$ & $1.4(0.2-12.9)$ & $2.5(0.6-10.3)$ \\
\hline Unintentional & $0.3(0.1-0.8)^{\mathrm{a}}$ & $0.1(0.01-0.5)$ & 0 (NA) & $1.2(0.2-5.8)$ \\
\hline \multicolumn{5}{|l|}{ Substance } \\
\hline Antidepressant & $0.6(0.3-1.4)$ & $0.5(0.2-1.1)$ & $0.4(0.04-3.5)$ & $0.4(0.1-1.7)$ \\
\hline Antiepileptic & $1.2(0.4-3.9)$ & $0.8(0.2-2.4)$ & $1.5(0.2-14.1)$ & $3.0(0.7-12.6)$ \\
\hline Isoniazid & $0.6(0.2-2.7)$ & $0.8(0.2-3.7)$ & 0 (NA) & $1.3(0.2-11.8)$ \\
\hline Stimulant & $3.9(1.1-14.5)^{\mathrm{a}}$ & $4.2(1.4-12.7)$ & $1.2(0.1-10.9)$ & $8.1(2.2-29.1)$ \\
\hline Anticholinergic & $0.6(0.2-2.1)$ & $0.7(0.2-2.4)$ & $1.8(0.2-17.2)$ & 0 (NA) \\
\hline Other & $1.0(0.4-2.5)$ & $1.3(0.6-3.1)$ & $1.6(0.3-9.5)$ & 0 (NA) \\
\hline \multicolumn{5}{|l|}{ Decontamination } \\
\hline Charcoal & $1.3(0.6-2.7)$ & $1.5(0.7-3.2)$ & $0.8(0.1-4.7)$ & $0.8(0.2-2.9)$ \\
\hline Bowel Irrigation & 1,000 (NA) & $7.7(0.9-68.4)$ & $4.3(0.4-43.8)$ & $5.3(0.9-32.3)$ \\
\hline Lavage & $7.6(0.9-61.3)$ & $4.3(1.1-17.1)$ & 0 (NA) & 0 (NA) \\
\hline \multicolumn{5}{|l|}{ Initial antiepileptic } \\
\hline Phenytoin & $3.7(0.8-17.8)$ & $2.1(0.6-7.2)$ & $5.1(0.8-31)$ & $2.0(0.4-10.3)$ \\
\hline Phenobarbital & $7.6(0.9-61.3)$ & $1.8(0.5-6.2)$ & 0 (NA) & $7.3(1.8-30.3)$ \\
\hline \multicolumn{5}{|l|}{ Initial presentation } \\
\hline Acidosis & $6.6(2.5-17.5)^{\mathrm{a}}$ & $3.2(1.4-7.0)$ & $11.0(1.2-97.7)$ & $0.7(0.2-2.8)$ \\
\hline Hyperthermia & $5.6(1.6-20.1)^{\mathrm{a}}$ & $5.1(1.8-14.2)$ & $10.4(1.8-61.4)$ & $4.4(1.2-16.1)$ \\
\hline Rhabdomyolysis & $8.6(1.9-38.9)^{\mathrm{a}}$ & $2.8(1.1-7.3)$ & $2.4(0.4-14.3)$ & $1.0(0.2-5.1)$ \\
\hline Hyperglycemia & $15.2(3.2-73.3)^{\mathrm{a}}$ & $3.3(1.2-9.1)$ & $4.5(0.4-53.2)$ & 0 (NA) \\
\hline Hypotension & $12.8(1.6-101)^{\mathrm{a}}$ & $5.3(1.6-17.5)$ & $7.6(1.4-41.7)$ & $1.5(0.3-7.5)$ \\
\hline
\end{tabular}

Univariate analysis for primary* and secondary outcome variables, presented with odds ratios and $95 \%$ confidence intervals

${ }^{\text {a }}$ Predictors which met the criteria for inclusion into logistic regression model 
the patients receiving phenytoin and phenobarbital treatment $7 / 12$ and 6/11 were intubated, respectively. Four out of five subjects with anoxic brain injury, 7/12 subjects with status epilepticus, and 30/49 intubated patients were hospitalized for greater than $72 \mathrm{~h}$. Of the 50 patients hospitalized for $>72 \mathrm{~h}, 19$ met no other outcome measure (status epilepticus, death, intubation, or anoxic brain inury; Fig. 1). Reasons for prolonged hospitalization in these 19 patients included: 1 aspiration pneumonia, 3 rhabdomyolysis, 11 persistent stupor/altered mental status, 1 cardiovascular instability, and 3 intractable acidosis.

Factors significantly associated in the univariate analysis with a complicated hospital course, endotracheal intubation, status epilepticus, and anoxic brain injury/death are listed in Table 4. Gender and age were not associated with complicating factors. Since stimulant-induced seizures had an association with a complicated hospital course, we performed a descriptive subanalysis of this group. Table 5 contains the results of this analysis. In this group, $66 \%$ were intubated, $50 \%$ were refractory to benzodiazepines, and $33 \%$ had status epilepticus.

Eight predictors met the criteria for entry into the logistic model. Factors independently associated with a complicated hospital course by logistic regression analysis are depicted in Fig. 2.

\section{Discussion}

Life-threatening complications from seizures include anoxia, respiratory failure, and status epilepticus $[9,10,13]$. Our study attempted to identify risk factors leading to these complications for drug-related seizures. While seizures of any cause account for $1.2 \%$ of all ED visits, the true incidence of drug-induced seizures is difficult to estimate [14]. Whatever the incidence, our results suggest that there is a relatively high complication rate $(60 \%)$ in this group. This is in contrast to the overall proportion of seizure-related presentations to the emergency department in which nearly $75 \%$ of patients are discharged home from the emergency department [14].

In our univariate analysis, we found seven factors to be associated with complications. However, in the multivariate analysis, only three predictors demonstrated statistically significant associations: stimulant exposure, initial acidosis, and hyperglycemia. When evaluated by substance type, we confirmed a trend identified in previous epidemiologic studies suggesting a declining morbidity associated with antidepressant exposures, probably because the relatively safer selective serotonin reuptake inhibitors have largely supplanted the more toxic tricyclic antidepressants [4]. Conversely, we demonstrated an increasing morbidity associated with stimulant exposures. This is congruent with
Table 5 Description of Stimulant exposures $(N=18)$

\begin{tabular}{|c|c|}
\hline VARIABLE & NUMBER \\
\hline Age (mean(SD)) & $27(11.3)$ \\
\hline Gender (male) & 14 \\
\hline \multicolumn{2}{|l|}{ Substance } \\
\hline Methamphetamine & 5 \\
\hline Cocaine & 7 \\
\hline MDMA & 3 \\
\hline \multicolumn{2}{|l|}{ Reason } \\
\hline Abuse & 11 \\
\hline Suicide & 4 \\
\hline Unintentional & 1 \\
\hline Body stuffer & 2 \\
\hline \multicolumn{2}{|l|}{ Presentation } \\
\hline Acidosis & 4 \\
\hline Hyperthermia & 5 \\
\hline Rhabdomyolysis & 2 \\
\hline Coma & 10 \\
\hline Hyponatremia & 3 \\
\hline Hyperglycemia & 3 \\
\hline Hypertensive crisis & 4 \\
\hline \multicolumn{2}{|l|}{ Treatment } \\
\hline No decontamination & 10 \\
\hline Charcoal & 7 \\
\hline Whole bowel irrigation & 3 \\
\hline Gastric lavage & 1 \\
\hline Phenytoin & 3 \\
\hline Phenobarbital & 4 \\
\hline Propofol & 3 \\
\hline Benzodiazepine & 18 \\
\hline Refractory to benzodiazepines & 9 \\
\hline Paralysis & 3 \\
\hline \multicolumn{2}{|l|}{ Complication } \\
\hline Anoxic brain injury & 1 \\
\hline Aspiration pneumonia & 3 \\
\hline Endotracheal intubation & 12 \\
\hline Status epilepticus & 6 \\
\hline
\end{tabular}

national trends published by the Drug Abuse Warning Network [15]. Our study also found the intent of use to be associated with complications, with unintentional exposures having a less complicated course than suicidal overdose or substance abuse. Although, this occurrence is likely consistent with the experience of clinicians and toxicologists, this study confirms the significance of these trends.

In accord with our findings, a recent study demonstrated a higher recurrence rate, higher severity, and clustering for seizures in those patients presenting with hyperglycemia [16]. Another recent study of patients with status epilepticus has identified hyperglycemia to be a novel marker for poor 
Fig. 2 Results of logistic regression model for complicated hospital course

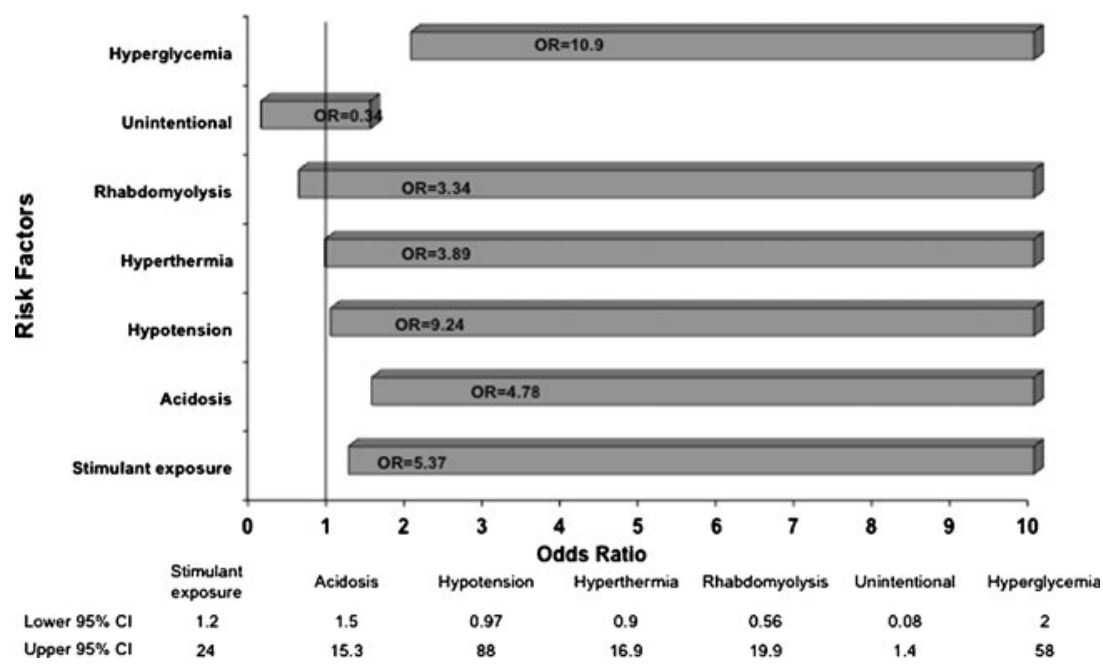

prognosis [17]. Other studies have confirmed the association between hyperglycemia and increased neuronal injury and mortality in patients with seizures, stroke, and traumatic brain injury [18-21]. Further, it has been demonstrated that hyperglycemia enhances glutamate accumulation in the brain [22]. Glutamate is a potent excitatory neurotransmitter, which enhances intracellular calcium flow and cell death but can also mediate seizure activity.

We did not expect this number of cases of hyperglycemia and do not have comprehensive information about the underlying presence of diabetes in our patient population. Future studies should gather information about diabetes prevalence and its impact on outcome. However, it seems likely that hyperglycemia is a consequence of sympathetic discharge and elevated circulating levels of catecholamines which are common during seizures. It is likely that hyperglycemia was not an indicator of diabetes prevalence but rather a marker for seizure duration or severity.

The relationship between acidosis and neuronal injury has similarly been established [23]. Enhanced acidosis may exaggerate neuronal injury by facilitating free radical formation, activating endonucleases or altering intracellular calcium regulation [24]. This injury is further exacerbated by the presence of acute hyperglycemia [25]. Future studies should attempt to clarify the association between hyperglycemia, acidosis, and seizure morbidity. Of course, it is unclear whether acidosis and hyperglycemia were contributors to complications or merely a manifestation of tonic-clonic muscle activity, secondary hypoxia, and generalized stress response. These are general incidental biomarkers, which may reflect seizure duration and also provide leads to future research.

An interesting finding in our study was the association between hyperthermia and morbidity. This was especially evident among subjects (66\%) with death or anoxic brain injury (Table 3). Although this predictor did not meet statistical significance in the logistic regression, the association between hyperthermia and epileptic brain damage has been previously demonstrated [4, 26, 27].

Limitations This study has several inherent limitations. First, health-care providers are not required to call the poison control center, and therefore, cases are acquired through passive surveillance. This may lead to a reporting bias such that only less common drugs or more complicated cases are reported. The majority of our cases, however, were associated with common medications and drugs of abuse. This lends some generalizability to our results.

Second, data was obtained via telephone and subject to misinterpretation and reporting bias. Investigators were limited to the nonuniform interpretations and assessments of the caller and not the investigators' direct bedside assessment. Further, estimating the dose is imprecise in overdose patients making the assessment of a doseresponse relationship inaccurate. Additionally, we could not obtain reliable information about other potential predictors such as "down time" prior to medical attention. Since these time estimates are often only "guesses," we chose to eliminate this predictor from our logistic model early in the study design.

Our sample encompassed a wide geographic region including multiple hospital types, which may have introduced treatment variations. While this enhances external validity, certain practices (i.e., the decision to intubate) may be based on available resources and personnel.

Our categorization of substances may not be the most accurate way to assess complications. But we specifically selected this classification scheme based on our previous studies [4]. For many clinicians working in acute situations, the classification scheme we used is a convenient and practical way to classify substances. We did not include coingestants into our logistic model because these were 
discounted as causal agents. Further, the inclusion of coingestants would compromise the power of the study to detect a difference.

Finally, due to the sample size, our study is not powered to assess for risk factors of specific complications (i.e., death) other than the primary outcome. On post hoc analysis, our sample size achieved a $79 \%$ power to detect a difference with regards to the primary outcome measure. We caution readers from drawing conclusions regarding the association of certain predictors (especially treatment factors) on secondary outcome measures, which contain wide confidence intervals. It is possible that treatment factors (i.e., decontamination choice, drug therapy) were not the proximate cause of a complication but a mere association arising from the necessity of aggressive treatment measures for an acutely ill patient.

Conclusions We have observed a number of risk factors associated with prolonged hospitalization, endotracheal intubation, status epilepticus, anoxic brain injury, and death for drug-induced seizures. Independent clinical factors associated with these complications of drug-related seizures include initial acidosis, hyperglycemia, and stimulant exposures. Other potential risk factors include hyperthermia, hypotension, and rhabdomyolysis. Unintentional exposures resulting in seizures appear to have a more benign course.

Open Access This article is distributed under the terms of the Creative Commons Attribution Noncommercial License which permits any noncommercial use, distribution, and reproduction in any medium, provided the original author(s) and source are credited.

\section{References}

1. Hauser WA, Kurland LT (1975) The epidemiology of epilepsy in Rochester, Minnesota, 1935 through 1967. Epilepsia 16(1):1-66

2. ACEP Clinical Policies Committee, Clinical Policies Subcommittee on Seizures (2004) Clinical policy: critical issues in the evaluation and management of adult patients presenting the emergency department with seizures. Ann Emerg Med 43(5):605-625

3. Isbister GK, Downes F, Sibbritt D et al (2004) Aspiration pneumonitis in an overdose population: frequency, predictors, and outcomes. Crit Care Med 32(1):88-93

4. Thundiyil JG, Kearney TE, Olson KR (2007) The evolving epidemiology of drug induced seizures reported to a poison control center system. J Med Toxicol 3(1):15-19

5. DeLorenzo RJ, Hauser WA, Towne AR et al (1996) A prospective population-based epidemiologic study of status epilepticus in Richmond, Virginia. Neurology 46:1029-1035

6. Pesola GR, Avasarala (2002) Bupropion seizure proportion amon new-onset generalized seizures and drug related seizures presenting to an emergency department. J Emerg Med 22(3):235-239
7. Alldredge BK, Lowenstein DH (1993) Status epilepticus related to alcohol abuse. Epilepsia 34(6):1033-1037

8. Alldredge BK, Lowenstein DH, Simon RP (1989) Seizures associated recreational drug abuse. Neurology 39(8):1037-1039

9. Towne AR, Pellock JM, Ko D et al (1994) Determinants of mortality in status epilepticus. Epilepsia 35(1):27-34

10. Sagduyu A, Tarlaci S, Sirin H (1998) Generalized tonic-clonic status epilepticus: causes, treatment, complications, and predictors of case fatality. J Neurol 245(10):640-646

11. Naranjo CA, Busto U, Sellers EM, Sandor P, Ruiz I, Roberts EA et al (1981) A method for estimating the probability of adverse drug reactions. Clin Pharmacol Ther 30:239-245

12. Treiman DM, Meyers PD, Walton NY, Collins JF, Colling C, Rowan AJ, Handforth A et al (1998) A comparison of four treatments for generalized convulsive status epilepticus. N Engl J Med 339:792-798

13. Koubeissi M, Alshekhlee A (2007) In-hospital mortality of generalized convulsive status epilepticus: a large US sample. Neurology 69(9):886-893

14. Huff JS, Morris DL, Kothari RU et al (2001) Emergency department management of patients with seizures: a multicenter study. Acad Emerg Med 8(6):622-628

15. Drug Abuse Warning Network (2004) Area profiles of drug-related mortality. DAWN Series D-31, DHHS Publication No. (SMA) 084346, Rockville, MD, 2008. Available at: http://dawninfo.samhsa. gov/pubs/mepubs/default.asp. Accessed January 10, 2009.

16. Huang CW, Tsai JJ, Ou HY et al (2008) Diabetic hyperglycemia is associated with severity of epileptic seizures in adults. Epilepsy Res 79(1):71-77

17. Rathakrishnan R, Sidik NP, Huak CY et al (2009) Generalised convulsive status epilepticus in Singapore: clinical outcomes and potential prognostic markers. Seizure 18(3):202-205

18. Huang CW, Cheng JT, Tsai JJ et al (2009) Diabetic hyperglycemia aggravates seizures and status epilepticus-induced hippocampal damage. Neurotox Res 15(1):71-81

19. Suh SW, Shin BS, Van Hoecke M et al (2008) Glucose and NADPH oxidase drive neuronal superoxide formation in stroke. Ann Neurol 64(6):654-663

20. Cherian L, Hannay HJ, Vagner G et al (1998) Hyperglycemia increases neurological damage and behavioral deficits from posttraumatic secondary ischemic insults. J Neurotrauma 15(5):307-321

21. Capes SE, Hunt D, Malmberg K et al (2001) Stress hyperglycemia and prognosis of stroke in nondiabetic and diabetic patients: a systematic overview. Stroke 32(10):2426-2432

22. Li PA, Shuaib A, Miyashita H et al (2000) Hyperglycemia enhances extracellular glutamate accumulation in rats subjected to forebrain ischemia. Stroke 31(1):183-192

23. Nedergaard M, Goldman SA, Desai S et al (1991) Acid-induced death in neurons and glia. J Neurosci 11(8):2489-2497

24. Hoxworth JM, Xu K, Zhou Y et al (1999) Cerebral metabolic profile, selective neuron loss, and survival of acute and chronic hyperglycemic rats following cardiac arrest and resuscitation. Brain Res 821(2):467-479

25. Rehncrona S (1985) Brain acidosis. Ann Emerg Med 14(8):770776

26. Lundgren J, Smith ML, Blennow G et al (1994) Hyperthermia aggravates and hypothermia ameliorates epileptic brain damage. Exp Brain Resuscitation 99(1):43-55

27. Yager JY, Armstong EA, Jaharus C et al (2004) Preventing hyperthermia decreases brain damage following neonatal hypoxicischemic seizures. Brain Resuscitation 1011(1):48-57 